\title{
Epistemic perceptualism, skill and the regress problem
}

\author{
J. Adam Carter $^{1}$ (D)
}

\begin{abstract}
A novel solution is offered for how emotional experiences can function as sources of immediate prima facie justification for evaluative beliefs, and in such a way that suffices to halt a justificatory regress. Key to this solution is the recognition of two distinct kinds of emotional skill (what I call generative emotional skill and doxastic emotional skill) and how these must be working in tandem when emotional experience plays such a justificatory role. The paper has two main parts, the first negative and the second positive. The negative part criticises the epistemic credentials of Epistemic Perceptualism (e.g., Tappolet, in: Clotilde (ed) Perceptual illusions. Philosophical and psychological essays, Palgrave Macmillan, Basingstoke, 2012; Tappolet in Emotions, value, and agency. Oxford University Press, Oxford, 2016; Döring in The Philos Quart 53(211): 214-230, 2003; Döring in Dialectica 61(3): 363-394, 2007; Elgin, in: Georg, Kunzle (eds) Epistemology and emotions, Ashgate Alderchot, Farnham, 2008; Roberts in Emotions: an essay in aid of moral psychology, Cambridge University Press, Cambridge, 2003), the view that emotional experience alone suffices to prima facie justify evaluative beliefs in a way that is analogous to how perceptual experience justifies our beliefs about the external world. The second part of the paper develops an account of emotional skill and uses this account to frame a revisionary form of Epistemic Perceptualism that succeeds where the traditional views could not. I conclude by considering some objections and replies.
\end{abstract}

Keywords Epistemic perceptualism - Perceptual theory of emotion · Regress problem · Foundationalism · Virtue epistemology · Sosa

J. Adam Carter

adam.carter@glasgow.ac.uk

1 Philosophy, University of Glasgow, Glasgow, UK 
Sense perception is epistemically important: it gives us justified beliefs and knowledge. Emotions, it seems, are also capable of doing this, at least in the right circumstances. The Perceptual Model offers an elegant explanation for how this is so: emotions are perceptions. They are perceptions of evaluative properties. As such, it is claimed that emotions play epistemic roles that are analogous to those played by sensory perceptual experience. For example, as Tappolet (2016) puts it:

On the basis of seeing a poppy as blue, you are prima facie justified in believing that the poppy is blue ... In the same way, it appears plausible to claim that when you feel the emotion of fear, say, this not only prompts you to believe that what you are afraid of is fearsome, but you are also prima facie justified in believing that what you are afraid of is fearsome (2016, p. 168). ${ }^{1}$

If this is right, then the Perceptual Model offers not only a straightforward explanation for how emotions can have a positive bearing on our intellectual lives. Even more-and this will be a central focus in what follows-the Perceptual Model offers the promise of a well-structured epistemology of value, one with secure epistemic foundations.

As Cowan (2016) captures this idea, the Perceptual Model:

[...] promises a way of halting the epistemic regress for evaluative beliefs, i.e., it identifies a source of evaluative justification that isn't itself in need of justification (Cowan 2016, p. 60).

In a similar spirit, Tappolet remarks that:

The claim that emotions constitute defeasible reasons for our evaluative beliefs fits well with a foundationalist account of justification according to which epistemic justification depends on a number of beliefs whose justification is independent of other beliefs (2016, p. 168).

In this paper, I am going to argue that the Perceptual Model, at least as it has been hitherto defended, fails to make good on this promise. The fly in the ointment is that emotions cannot be vindicated as 'regress stoppers' in the sense that proponents of the Perceptual Model of would need them to be in order to secure a suitably plausible form of (modest) foundationalism. This, it will be shown, is the case regardless of whether one attempts to vindicate the traditional Perceptual Model through epistemic externalism or epistemic internalism.

But, all is not lost. Rather than to jettison the Perceptual Model entirely, my suggestion is that our best prospects for a well-structured epistemology of value will involve a highly revisionary form of the Perceptual Model, one that (unlike extant versions) gives emotional skill — and in particular, what I call generative emotional skill and doxastic emotional skill-a central place. I will show how emotional experience, suitably backed by these skills working in tandem, can stop a

\footnotetext{
${ }^{1}$ See, for example, Tappolet (2012, 2016), Döring (2003, 2007), Elgin (2008) and Roberts (2003).
} 
justificatory regress, even if bare emotional experience, as such, cannot. I conclude by considering several objections to the view proposed and offer some replies.

\section{2}

Four brief clarifications about the Perceptual Model (and specifically, about the epistemological dimension of the Perceptual Model) will be useful at the outset. Firstly, and importantly, the prima facie justification claim being made by proponents of the Perceptual Model is an epistemological claim. It is as such distinct from Perceptual Model's metaphysical thesis about the nature of emotion as a kind of perception. We can distinguish these two theses as follows:

Metaphysical Perceptualism (MP): Emotions are a kind of perceptual experience of evaluative properties.

Epistemic Perceptualism (EP): Emotions are sources of immediate prima facie justification for evaluative propositions.

It is epistemic perceptualism-hereafter, EP-rather than the metaphysical thesis (MP) that will be the focus of what follows.

Secondly, note that, regardless of whether the truth of MP would motivate the truth of EP, MP doesn't entail EP. ${ }^{2}$ One could, for instance, conceivably hold that emotions are perceptual experiences of evaluative properties while maintaining that, given certain epistemological disanalogies between emotions and perceptions, beliefs formed via emotion don't enjoy the kind of prima facie justification that beliefs formed via perception do. On such a view, MP would seem to be rendered epistemically toothless. It's unsurprising then that most proponents of MP also go in for the epistemological claim EP.

Thirdly, note that the prima facie justification at issue in EP is both (i) immediate and (ii) defeasible. It is immediate in the sense that it is a kind of positive epistemic status a belief acquires that doesn't depend on any inferences one makes. ${ }^{3}$ According to EP, the very experience you have of admiring the stranger itself suffices to make your corresponding belief that the stranger is admirable prima facie justified for you. But — and herein is the importance of the 'prima facie' qualifiersuch a belief is defeasible, in the sense that it can be defeated by new beliefs you might acquire. Suppose, for example, you find yourself admiring a stranger only to (shortly afterwards) hear from a liar that you've ingested a drug that randomly

\footnotetext{
${ }^{2}$ See Cowan (2016, p. 60) for helpful discussion on this point. As he puts it, 'an epistemic premise is required in order to get from Perceptualism to Epistemic Perceptualism'.

3 Relatedly, it should be made explicit that the term emotional justification has been used by (among others) Echeverri Saldarriaga (2017) and Greenspan (1988) to refer to the justification of emotions, and this usage takes for granted that emotions can be themselves justified. The kind of emotional justification at issue in EP concerns, specifically, the epistemic justification of belief by emotion (and not the other way around).
} 
manipulates your affective responses. The acquisition of such a new belief will (at least on standard ways of thinking about epistemic defeat ${ }^{4}$ ) function as a defeater for the prima facie justification you originally had for your belief that the stranger is admirable. What bears emphasis, as proponents of EP see it, is that prior to acquiring any such defeater, you were already immediately justified in believing what you did simply in virtue of having the kind of experience you had which gave rise to your belief.

Fourthly, it is worth registering a clarification about the scope of EP. Even those who reject EP might be attracted to the idea that emotions can provide justification for a special class of introspective beliefs: beliefs an agent has about her own emotional experiences. ${ }^{5}$ EP doesn't just apply to introspective beliefs. Your fear of a snarling dog, according to EP, affords you prima facie justification for believing something about the dog-viz., that it is fearsome-and not just something about your mental life, e.g., that you are afraid of it.

Suppose you believe that hissing cobra in front of you is fearsome. You believe this along with a number of related things: that it has sharp teeth. That teeth can break the skin. That teeth breaking the skin can cause pain. That pain is generally unpleasant, etc.

Question: How must such beliefs be interrelated in order to help justify your belief that the cobra is fearsome ${ }^{6}$ One story here-albeit, not a very popular oneis given by coherentism. ${ }^{7}$ On this view, all justified beliefs, evaluative or otherwise, are justified because they belong to a coherent set of beliefs that support them (i.e., beliefs that are mutually supporting in that they lend deductive, inductive, or abductive support to other members). ${ }^{8}$ Coherentists accordingly think that the beliefs that provide rational support for our beliefs derive their justification exclusively from further beliefs, and not from anything located outside the circle of belief, including experiences-perceptual, emotional or otherwise.

That coherentism marginalises the epistemic role of experience is widely thought to be problematic when what's at issue is the justification of our beliefs about the external world reached through sense (e.g., visual) perception. ${ }^{9}$ But such a

\footnotetext{
4 See, for example, Pollock (1986).

5 For discussion on this point, see Pelser (2014, p. 107).

6 This way of setting up the question owes to Sosa (1980, p. 5).

7 Of course, the sceptic about the evaluative challenges the validity of this question by denying that your belief that the cobra is fearsome is epistemically justified for you, no matter how you organise your mind, and so no matter what else you think or why you think it. Such a view could be reached through various routes (e.g., through epistemic error theory, through a commitment to Cartesian standards of certainty, through Pyrrhonian strategies, such as via the modes of Agrippa, etc.) but I am going to simply table this position, assuming for our purposes that it is false.

${ }^{8}$ For a seminal defence of this view, see for example BonJour (1985).

9 See Lyons (2009) for discussion. See also Carter and Littlejohn (2019).
} 
marginalising of experience seems at least as worrisome when what's at issue is the justification of our evaluative beliefs, viz., beliefs about what's admirable, fearsome, disgusting, etc. ${ }^{10}$ To see why, just consider that a coherentist about the justification of evaluative beliefs-viz., an 'evaluative coherentist'-must accept the following strong rejectionist claim about the epistemic import of emotional experience: that no emotional experience, under any circumstance, can justify (to any extent) any evaluative proposition.

Such 'strong rejectionism' is much stronger than merely denying EP. Even many contemporary critics of EP will be unwilling to go so far. This is because even critics of EP maintain that sometimes (even if perhaps under very specific circumstances) emotions can play a justificatory role. ${ }^{11}$ But it's an unavoidable commitment of the core idea of evaluative coherentism that the justification we have for evaluative propositions cannot under any circumstances derive from anything outside the web of one's beliefs. ${ }^{12}$ And so from evaluative coherentism, 'strong rejectionism' would simply follow.

Where to go from here? Given that infinitism is notoriously fraught, ${ }^{13}$ all signs at this point are indicating that a well-structured evaluative epistemology will need to be a foundationalist one.

\footnotetext{
${ }^{10}$ Regardless of whether coherentism is viable more generally in epistemology (its decline in popularity suggests it is not), it is especially poorly suited to explain the structure that underlies our justified evaluative beliefs. To see why this is so, just suppose that the hissing cobra we are discussing is coiled up in your dresser drawer. You hear some gentle noises—unsure what might be making the sound-open the drawer, see the cobra, and are terrified. Your belief that the cobra in your drawer is fearsome is of course well justified. This simple case gives us all the tools we need to see why coherentism about evaluative beliefs is deeply problematic. Here is the argument, which begins with two observations: You're justified in believing that what is in your drawer is fearsome after you open the drawer, but not before. Some difference between these two beliefs (before, and after) must account for this difference in justification. According to the coherentist, the only possible relevant difference between justified and unjustified beliefs is how well they cohere with the rest of the believer's beliefs. But, in terms of how well these beliefs cohere, the belief that the object in your drawer is fearsome coheres with the rest of your beliefs equally well before you open the drawer and after you open the drawer. And this means that coherentism implies the absurd result that either the belief could be justified before you open the drawer and after or it couldn't be justified before your open the drawer or after. See Carter and Littlejohn (2019 Chap. 1) for further discussion.

${ }^{11}$ See, for example, Brady $(2010,2013)$. Note, however, that on Brady's view, emotions can under certain circumstances give rise to what he calls 'proxy justification', something which he holds to be distinct.

12 As Davidson (1986, p. 126) pithily captures the idea: '[w]hat distinguishes a coherence theory is simply the claim that nothing can count as a reason for a belief except another belief'. It is worth noting that some versions of coherentism attempt to allow experiences to be part of the relevant web of beliefs. However, as Olsson (2014) points out, it may be that such views are better described as forms of weak foundationalism.

${ }^{13}$ On this view, (i) a chain of justifiers justifies a given evaluative belief only when it forms an infinite series of non-repeating justifiers; and (ii) no belief can be justified without support from a further justifier that belongs to such a series. Interestingly, and setting aside obvious other problems with evaluative infinitism, most notably here, the Finite Mind Objection (e.g., Turri and Klein 2014), a commitment to SR can't be sidestepped by ditching evaluative coherentism for something like evaluative infinitism. Both views would be equally committed to the claim that that an evaluative belief is justified iff it is supported by further justified beliefs. And commmitment—even though coherentism and infinitism uphold it in very different ways-is enough to imply SR.
} 
Here's the core idea:

Evaluative foundationalism (EF) (i) All justified evaluative beliefs are justified because of support from further justified beliefs or because they are justified without such support. (ii) For any justified evaluative belief, it either is a properly basic evaluative belief or it derives its justification from such beliefs.

Unlike evaluative coherentism (as well as infinitism), evaluative foundationalism (hereafter, EF) is at least compatible with the thought that-in some circumstances-the experience of fear is enough to prima facie justify a thinker in believing that something is fearsome, e.g., that your experience of feeling disgust upon gazing at a carcass is enough to justify your belief that what you're looking at is disgusting.

Even more, a foundationalist epistemology is paradigmatically well structured; it commits one to neither infinite nor circular chains of reasoning, nor-given that foundational beliefs are justified — to epistemically arbitrary foundations. ${ }^{14}$

Does EP entail evaluative foundationalism, as some proponents of EP seem to suggest? If so, this would seem like a very good thing indeed. It would mean that the benefits of having a well-structured evaluative epistemology would 'come free' with the view. This would make for a very attractive offer. But unfortunately, things here are not so simple. For starters, evaluative foundationalism is secured through EP only if emotions stop the regress of justification by constituting a justifier for our foundationally justified beliefs.

But here a question arises: what exactly are the conditions under which something does this-viz., stop the regress of justification by constituting a justifier for our foundationally justified beliefs? This is a notoriously difficult question. We can distinguish two positions:

Cartesian Foundationalism: Something stops the regress of justification by constituting a justifier for our foundationally justified beliefs iff this is something distinct from a belief that provides the thinker with certainty that her foundational belief is true. ${ }^{15}$

Modest Foundationalism: Something stops the regress of justification by constituting a justifier for our foundationally justified beliefs iff this is something distinct from a belief that provides the thinker with adequate albeit fallible support for her foundational belief. ${ }^{16}$

Most will agree that emotions don't very often, if ever, provide a thinker with certainty. And that's a problem if it turns out that Cartesian Foundationalism offers the best answer to the question of what stops an epistemic regress.

\footnotetext{
14 On Wittgenstenian contextualism (e.g., Williams 2007), the structure of justified beliefs is a foundational one, however, the foundations themselves are not fixed in place. For a more recent variation on this kind of view, see Greco (2017).

15 Defenders of this view include, along with Descartes, Schlick, Hempel, C.I. Lewis, and Chisholm.

16 See Carter and Littlejohn (2019 Chap. 1) for an overview.
} 
For reasons that won't concern us here, Cartesian Foundationalism, though once popular, has been mostly abandoned, ${ }^{17}$ and with it, any demand for such certainty. I'm going to assume without argument that the much less contentious Modest Foundationalism best captures what would be needed to halt an epistemic regress.

With this assumption in place, it follows that EP promises a way of halting the epistemic regress for evaluative beliefs provided emotions furnish a thinker with adequate albeit fallible support for her (would-be) foundational beliefs. What counts as adequate here? There's very little consensus concerning sufficiency for such adequacy by modest foundationalists. However, an uncontroversial and wholly plausible necessary condition is the following: emotions provide a thinker with adequate albeit fallible support for foundational beliefs only if emotions at least prima facie justify those beliefs. From these claims, it follows that emotions can halt the epistemic regress for evaluative beliefs only if emotions at least prima facie justify those beliefs, which is logically equivalent to: emotions can halt the epistemic regress for evaluative beliefs only if EP is true.

How hard can it be, then, for emotions to stop an epistemic regress, by being the sort of things that suffice to prima facie justify beliefs?

As Tappolet sees things, it's not hard at all. And this is because she thinks that the conditions that would need to be satisfied for any source to deliver immediate prima facie defeasible justification are, as she reckons, 'quite minimal'. Her remarks here are interesting:

Prima facie justification is quite a minimal epistemic status, which is not that difficult to attain. If you are afraid of a dog, it is surely something that makes your belief that the dog is fearsome prima facie justified. In the same way, it is plausible that the belief that your friend's accomplishment is admirable is prima facie justified given the admiration that you feel. One should, it seems, grant that an emotion can confer prima facie justification (2016, p. 40).

Here, though, we need to be careful. It's one thing to say that prima facie justification is a minimal epistemic status in the sense that, on a continuum of positive epistemic statuses, prima facie justification lies at the 'low end'. This point should be uncontroversial. But it certainly wouldn't follow from this uncontentious claim that that prima facie justification is a minimal epistemic status in the sense that the conditions that must be in place for a way of belief forming to issue prima facie justification are such that not much is needed (by way of the epistemic credentials of that way of belief forming) in order to satisfy them. (It might be, after all, that even positive epistemic statuses like prima facie justification that lie on the low end of an envisioned continuum are such that only belief forming processes

\footnotetext{
${ }^{17}$ For an apt historical overview, including a discussion of Sellars' (1956) critique of Cartesian foundationalism, see Sosa (1997).
} 
with epistemically robust credentials are capable of generating beliefs that immediately secure those statuses). And at any rate, it remaians an entirely open question whether emotions would in fact bear such epistemic credentials, however they would best be spelled out. Relatedly_and even more problematically in so far as we are taking seriously the aim of providing a well-structured evaluative epistemology - the cost of epistemic laxity in a specification of the conditions that must be in place for a way of belief forming to issue prima facie justification would be epistemically weak foundations. This is a high-risk cost for any would-be nonsceptical evaluative epistemology.

The above considerations, I think, should leave us suspicious of Tappolet's transition from (i) the idea that prima facie justification is a minimal epistemic status, to (ii) the claim that conditions that must be in place for a way of belief forming to issue prima facie justification are minimal in the sense that 'very little' is needed in order to satisfy them. More by way of argument is needed. To that end, let's consider now how we might spell out in a substantive way the kind of epistemic credentials emotions would have to have in order to be the sort of things that suffice to prima facie justify beliefs.

\section{5}

There is an extensive body of externalist literature that, though divided about whether to try to make the case on a priori or a posteriori grounds, is committed to a strict reliability constraint on all sources of prima facie justification, including perception. Graham (2011), for example, suggests the following constraint, embraced by Burge (1993) and others:

(Reliabilism)-Perceptual Prima Facie Justification (Reliabilism-PPFJ) Perceptual belief enjoys prima facie justification only if perception produces mostly true beliefs. ${ }^{18}$

It's beyond the scope of what I can do here to try to defend Reliabilism-PPFJ in the case of perception. ${ }^{19}$ Rather, I want to register two points. First, the constraint on perceptual prima facie justification specified by (Reliabilism-PPFJ) seems plausible when we think about just why it is that (for instance) simply taking wild guesses at face value isn't a viable route to acquiring prima facie justification. Emotions, we think, wouldn't confer prima facie justification if they were epistemically on par with guesses, even if they were in many other respects analogous with perceptions (as proponents of the Perceptual Model claim).

Second, if (Reliabilism-PPFJ) is correct, then absent some very good reason otherwise, we should expect the same constraint to hold in the case of emotion as in the case of other forms of perception. That is, if perceptual belief enjoys prima facie justification only if perception produces mostly true beliefs, then beliefs formed via

18 (Graham 2011, p. 468).

${ }^{19}$ See, however, Carter and Pritchard (2019). 
emotion enjoy prima facie justification only if beliefs formed via emotion produce mostly true beliefs.

Of course, if such a reliability requirement would apply to emotion, then absent the collateral empirical claim that emotions really are reliable (enough), it would follow that EP is false (and all the worse for the suggestion that emotions are regress stoppers).

In the face of the above 'reliability problem' for proponents of EP, both overriding and undercutting strategies have been advanced. The former take the reliability requirement (on sources fit to confer prima facie justification) as a valid epistemic requirement and then attempt to show how emotions meet it. Undercutting strategies do not attempt to show how EP can meet the requirement, but rather, suggest the requirement is mistaken (while at the same time attempting to avoid over-permissiveness in doing so).

One overriding strategy is suggested by Pelser (2014) as follows:

[...] virtually the whole range of virtues, both intellectual and moral, are in part dispositions to have the right emotions toward the right objects at the right time and to the right degree. Insofar as some people possess some virtues, therefore, the unreliability objection does not undermine the justificatory thesis of emotion" (Pelser 2014, p. 116).

That virtuous folks have (in short) reliable emotions is, it should be emphasised here, compatible with emotions not giving prima facie justification to the relevant kinds of beliefs when formed by unvirtuous or even ordinary people. While countenancing this fact might be compatible with some ways of formulating a justificatory thesis about emotion, it's not compatible with EP. Consider that, in the case of perception, even the unvirtuous can gain prima facie justified beliefs by relying on it. If EP is aiming for the kind of prima facie justification claim that perception enjoys, the point about the virtuous that Pelser appeals to isn't going to be enough to secure it. The virtuous are a minority; but those who enjoy prima facie perceptual justification are presumably not.

This point can be helpfully resituated in the context of the regress problem. Part of Moderate Foundationalism's appeal as a response to the regress problem is that it is an anti-sceptical strategy; it offers a way to make good on the thought that most people have the justified beliefs and knowledge we would pretheoretically attribute to them. If the only kind of moderate foundationalism EP is capable of securing is one with limited foundations (or: foundations just for the virtuous few), then much of its anti-sceptical appeal is lost. This general philosophical point is not a new one, and it's one that Sosa (among others) have levelled at Descartes. As Sosa (1980) puts it, in the context of challenging the anti-sceptical potential of Cartesian foundationalism:

once we restrict ourselves to what is truly obvious in any given context, very little of one's supposed common sense knowledge can be proved on that basis (1980, p. 5).

Likewise, if the kind of foundationalism EP is restricted to is one with substantially restricted foundations (only the emotions of the virtuous minority, and 
no others), then it seems that very little of the total stock of common sense evaluative knowledge could be proved on this basis.

\section{6}

At the end of the day, though, the proponent of EP (in principle, at least) needn't be required to provide a convincing overriding response to the worry about reliability so long as they have a good undercutting strategy on hand. Such a strategy is attempted by proponents of EP who align themselves not with epistemic externalist approaches to prima facie justification but with epistemic internalist accounts. Consider, for example, the phenomenal conservativist view of prima facie justification defended by (among others ${ }^{20}$ ) Huemer (2001) and Tucker (2010).

Phenomenal conservativism (PC): If it seems to $\mathrm{S}$ as if $\mathrm{P}$, then $\mathrm{S}$ thereby has at least prima facie justification for believing that P. (2001, p. 99)

Two clarifications here. Firstly, PC is not meant to cover all seemings. At least as defended by Huemer, the view is supposed to cover three kinds of seemings: perceptual, memorial and intellectual seemings. Secondly, Huemer thinks that these three kinds of seeming-as-if states both (i) suffice for prima facie justification; and (ii) are suitable for playing the role of epistemic foundations. ${ }^{21}$

Here isn't the place to try to defend or reject PC as such. Rather, what's of interest is that if PC is correct, then-at least provided emotional seemings can be defended as on par with the kind of perceptual, memorial and intellectual seemings ${ }^{22}$ that PC privileges - a theoretical avenue opens up for undercutting those arguments that seek to challenge EP by appealing to the claim that only reliable processes can prima facie justify beliefs. The idea would be that it doesn't matter whether emotions are reliable; if a liberal version of PC is correct, they can both prima facie justify beliefs and serve as epistemic foundations simply because they involve a 'seeming-as-if' state of a certain sort (perceptual, memorial, intellectual, or-as we're envisaging-emotional).

A proponent of EP who wants to rest her case on the material adequacy of a liberal version of PC, I want to now suggest, faces a dilemma. To appreciate the dilemma, first consider this proposed objection to the view due to Markie (2005):

Mental processes that are incapable of producing prima facie justified beliefs can nonetheless determine how things seem to us. Suppose that we are prospecting for gold. You have learned to identify a gold nugget on sight but I

\footnotetext{
${ }^{20}$ The most notable specific version of phenomenal conservativism, which is restricted to the case of perception, is the dogmatist view of perceptual justification defended in various places by Pryor (2000, 2004).

21 See Huemer (2001, p. 102). Cf., Goldman (2008) for criticism.

22 Though, the matter of why this is so is not entirely clear. As Markie (2010) puts it, 'Yet, if we ask why such a seeming renders the corresponding beliefs prima facie justified when desiring, imagining and guessing do not, phenomenal conservatism's answer is: "It just does." It's a brute, necessary, self-evident fact (2010, p. 70).
} 
have no such knowledge. As the water washes out of my pan, we both look at a pebble, which is in fact a gold nugget. My desire to discover gold makes it seem to me as if the pebble is gold; your learned identification skills make it seem that way to you. According to (PC), the belief that it is gold has prima facie justification for both of us. Yet, certainly, my wishful thinking should not gain my perceptual belief the same positive epistemic status of defeasible justification as your learned identification skills (2005, pp. 356-357).

Markie's case looks initially very problematic for PC, and this point has been echoed in different ways by, among others, McGrath (2013) and Goldman (2008). ${ }^{23}$ How should PC deal with such cases?

The dilemma facing a proponent of EP who aligns herself with PC is this: there is pressure for the proponent of PC to (perhaps rather substantially) restrict the kinds of seeming-as-if states that count as those that generate prima facie justification in order to deal with Markie-style counterexamples. Although such a restriction could perhaps help PC to sidestep such counterexamples, it would at the same time raise the bar for what is required to rule-in emotional seemings as prima facie justifiers, alongside perceptual, memorial and intellectual seemings that PC already countenances.

But then - and this is the other horn of the dilemma-if we construct a principled and more liberal formulation of PC that would rule-in emotional seemings, ${ }^{24}$ Markie's counterexample will accordingly be even more difficult to handle.

Neither horn of the dilemma looks very good for the proponent of EP whose epistemic credentials are supposed to rest on a liberal version of PC. The dilemmafor ease of reference, call it the 'Markie dilemma' - can be represented then as follows:

Liberality of Result
PC

\begin{tabular}{ll}
\hline Liberal & Emotional seemings are ruled in, but then Markie's counterexample looks decisive. \\
Restrictive & Markie's counterexample is deflected, but then it is more difficult for EP to rely on PC.
\end{tabular}

\footnotetext{
${ }^{23}$ For a notable version of this kind of objection framed in terms of cognitive penetration, see Siegel (2012).

24 One voice of scepticism on the specific point of ruling in such emotions is raised by Hasan and Fumerton (2017, Sect. 5). As they put it, 'It strikes many epistemologists that these views make getting justification for one's beliefs too easy. Perhaps sensations are representational states, and perhaps there is the kind of representational state that Huemer and other phenomenal conservatives call an appearing or a seeming, but as why should we assume that they accurately represent the world around us? Fear is a representational or propositional state, but from the fact that I fear that there are ghosts, it hardly seems to follow that I have a prima facie justification for believing that there are ghosts'.
} 
Taking stock, it looks as though EP is, all things considered, not in very good shape. Emotions, it would appear, are not promising candidates for regress stoppers. In order to argue otherwise, one would need to, at some point, bite some kind of bullet or at least do a bit of special pleading. Here is the overall situation, in outline: Suppose the proponent of EP attempts to rest her epistemic credentials on an externalist epistemology. Doing so would, one way or another, require demonstrating that emotions are generally reliable, and generally reliable in a way that would suffice to render emotions plausible epistemic regress stoppers. ${ }^{25} \mathrm{We}^{\text {' ve considered }}$ in previous sections why this would be a tall order. But whereas the proponent of EP who 'goes externalist' is at least committed to the validity of this tall order and must show how EP can meet it, the proponent of EP can avoid such an explanatory demand entirely by 'going internalist', e.g., by embracing something like PC. Such a strategy, though, will need to find a way to explain how emotions can stop an epistemic regress even though (presumably) not any seeming is a regress stopper. This strategy faces Markie's dilemma just raised in the previous section. Of course, one could defend EP along internalist lines, but remain agnostic (or sceptical) about whether the level of prima facie justification emotions generate suffices to stop an epistemic regress. This strategy, though, is in an important way epistemically negligent; it would avoid the costs associated with the other strategies only by effectively abandoning any attempt to secure a well-structured evaluative epistemology.

None of the above strategies looks promising. ${ }^{26}$ Of course, one commonality of each strategy is that it retains EP in its traditional form. For those who are not inclined to such special pleading in order to retain EP, there are still some remaining (non-skeptical) kinds of positions left on the table. One kind of position, nonperceptual modest foundationalism, attempts to show how emotions can play a role in regress stopping even if, contrary to the Perceptual Model, emotions aren't themselves perceptual experience of evaluative properties which are sources of immediate prima facie justification for evaluative propositions. Another kind of option is to opt for a revisionary form of EP, one that denies EP's core claim as it stands, while defending (unlike non-perceptual modest foundationalism) a version of EP on which emotions can serve as regress stoppers.

In the remainder of the paper, I'm going to show how I think this latter of these two strategies may have some considerable promise, and I'll conclude by showing how it has some key advantages over the former.

\footnotetext{
${ }^{25}$ Note that one constraint here-highlighted previously in the discussion of Pelser (2014) - is that whatever stock of foundations that is afforded by emotions in their capacity as regress stoppers must not be substantially restricted; otherwise, very little of the total stock of common sense evaluative knowledge could be proved on their basis.

${ }^{26}$ It's worth noting that the first strategy is going to be difficult to defend even if reliabilism is a priori true. This is because EP is properly vindicated only in conjunction with a suitable non-scepticism. The cost of going the first route, for one who wants to defend a non-sceptical EP, is that it's not at all clear that emotions as, as a kind, are reliable enough.
} 


\section{8}

We noted previously that the matter of what kind of thing can stop a regress is answered differently by Cartesian as opposed to modest foundationalists.

One specific difference between the views that's already been highlighted is that the former maintain that a regress can be stopped only by certain, indubitable foundations, whereas the latter denies this. However-and importantly in what follows - there is a further difference between the two views which bears relevance to how we might envision a foundational role for emotions to play within a modest (evaluative) foundationalism.

This further difference between Cartesian and modest foundationalism concerns the way the two positions view experience as bearing on epistemic justification and knowledge. According to the Cartesian foundationalist, experience can bear epistemically on the justification of a belief only by—as Sosa (2009) puts it:

[...] presenting itself to the believer in such a way that the believer directly and non-inferentially believes it to be present, and can then use this belief as a premise from which to reach conclusions about the world beyond experience (2009, p. 89).

If this is right, then whatever kind of experience, distinct from belief, could serve as a regress stopper would have to satisfy not only a certainty condition (i.e., it must provide the thinker with certainty that her foundational belief is true), but it must also satisfy a kind of presentational condition such that the experience would bear on the justification of a foundational belief by constituting a kind of directly 'apprehended' given.

The modest foundationalist, to be clear, is constrained neither by the Cartesian foundationalist's certainty requirement, nor by the Cartesian foundationalist's distinctive way of thinking of the way experience is supposed to bear on a foundational belief's justfication.

According to an alternative conception which Sosa himself finds attractive and attributes initially to Thomas Reid:

Experience can bear epistemically on the justification of a foundational perceptual belief by appropriately causing that belief (2009, p. 89).

I'm going to take this Reid/Sosa idea as a starting point for thinking about how to make good on a (albeit, revisionary) version of EP that's reconcilable with modest foundationalism. In particular, I'm going to take as a starting point that emotional experience can bear epistemically on the justification of a foundational evaluative belief by appropriately causing that belief. Let's now see where this guiding idea leads us. 
The working idea that emotional experience can bear epistemically on the justification of a foundational evaluative belief by appropriately causing that belief would help us secure a viable modest evaluative foundationalism only if emotions really can and do appropriately cause-and not merely cause-a sufficiently rich stock of foundational evaluative beliefs.

What might such appropriate causation involve? One natural idea is that reliable causation would surely suffice for appropriate causation, regardless of whether reliable causation is necessary. But such a thought is premature. Consider the following case.

\begin{abstract}
METAINCOHERENT EMOTER: Tim's emotional life reliably tracks evaluative properties in the following sense: Tim's fear is triggered when and only when something fearsome is present; Tim's admiration is triggered when and only when Tim is in the presence of someone or something admirable, etc. Because Tim invariably takes his emotional experiences at face value, Tim maximally reliably forms true beliefs about the evaluative world, and in this respect, Tim's emotions reliably cause true evaluative beliefs. The twist in the tail, however, is that Tim's emotions are unbeknownst to him being 'triggered' at just the right times by a benevolent demon who ensures that Tim, for instance, experiences fear only in the presence of something fearsome, admiration only in the presence of the admirable, etc. If the benevolent demon were not assisting in this way, we may assume further that Tim's emotions would not reliably track value: although he would continue to invariably take his emotional experiences at face value, the emotional experiences themselves would not reliably be triggered by the presence of the relevant values, and so the corresponding beliefs he would form would be reliably false.
\end{abstract}

In METAINCOHERENT EMOTER, Tim's emotional experiences (which he invariably takes at face value - that he is disposed to do this is something the demon doesn't tinker with) reliably cause him to form true evaluative beliefs. But it seems implausible to suppose that Tim should count as prima facie justified in taking his emotions at face value as he does, despite that doing so is a perfectly reliable way to do so. $^{27}$

\footnotetext{
27 This case bears some structural resemblances to, but also some important structural differences from, two kinds of cases which are already familiar in the externalist epistemology literature and which don't involve emotion: Kelp's (2016) epistemic Frankfurt case and Pritchard's (2010, pp. 48-49) 'Temp' case. METAINCOHERENT EMOTER like the other two case types involves a benevolent demon. In epistemic Frankfurt cases, however, the demon doesn't actually intervene; as for Pritchard's case of Temp, a benevolent demon intervenes in a fortuitous way for the subject, but in a way that manipulates the subject's external environment rather than manipulating the character of the subject's own cognitive (and conative) responses to it. Finally, I should add that I'm referring to this as a kind of 'metaincoherence' case because it shares one important feature with traditional metaincoherence examples (e.g., TrueTemp, Norman the Clairvoyant, etc.) that have been appealed to in the reliabilist literature. Specifically, in the classic metaincoherence cases as well as in this case, there is a mismatch between the source of the reliability of the relevant process and the agent's conception of this source.
} 
Tim's emotions don't competently cause his foundational beliefs. After all, that his beliefs are correct are not due to any competence of his, but to a benevolent angel who is spoonfeeding him emotions that he simply takes at face value. Remove the angel, holding fixed Tim's own cognitive contribution to his successes (which is just to take his emotions, whatever they are, at face value) and Tim's beliefs are reliably false.

If we are going to have a chance of making good on the idea (consonant with moderate foundationalism) that emotional experience can bear epistemically on the justification of a foundational evaluative belief by appropriately causing that belief, we need a better story for what such appropriate causation involves.

One thing Tim seems to lack is any kind of 'emotional skill', despite his benevolentdemon assisted reliability in forming true beliefs about the evaluative world by taking his emotions at face value.

The METAINCOHERENT EMOTER case suggests that Tim would certainly 'level up' his emotional skills if he could somehow do himself what the demon was doing for him in METAINCOHERENT EMOTER. In particular, in order to render the demon superfluous, it would seem that Tim would need to gain a disposition that, specified as a function, takes the presence of values as inputs and outputs emotions that correspond to those values reliably.

Would the acquisition and reliable exercise of such a skill be enough for us to suppose that Tim's emotions are competently causing his corresponding beliefs? Granted, such a skill would render the demon from METAINCOHERENT EMOTER superfluous. Yet, it would not in itself be enough. To see why, just consider the following 'inverted' variation on the previous case:

INVERTED METAINCOHERENT EMOTER: Tim*'s emotional life reliably tracks evaluative properties in the following sense: Tim*'s fear is triggered when and only when something fearsome is present; Tim*'s admiration is triggered when and only when Tim* is in the presence of someone or something admirable, etc. Because Tim* invariably takes his emotional experiences at face value, Tim* maximally reliably forms true beliefs about the evaluative world, and in this respect, Tim*'s emotions reliably cause true evaluative beliefs. The twist in the tail, however, is that the intervention of a benevolent demon explains why Tim* reliably takes his emotions at face value when he does. If the benevolent demon were not assisting in this way, we may assume further that Tim*'s having the experience of fear would not reliably lead him to form any corresponding true belief about something's being fearsome (rather, he would believe it to be funny or disgusting, etc.). In such a case, Tim*'s emotional experiences themselves (unlike in METAINCOHERENT EMOTER) would be reliably triggered by the presence of the relevant values, but-absent the intervention of the benevolent demon-he would not go on to reliably form the relevant true beliefs. 
In this 'inverted' version of the previous case, Tim*'s emotions are reliably triggered by the presence of the relevant values, and that they are so triggered is not down to the intervention of any benevolent demon (as was the case in METAINCOHERENT EMOTER). Rather, it is because of he is cognitively and conatively constituted as he is. Moreover, in this inverted version of the case, Tim* reliably goes on to form the corresponding true beliefs.

Importantly, though, Tim*'s emotions don't competently cause his foundational beliefs any more than Tim's did. After all, that his beliefs are correct are not due to any competence of his, but are down to the intervention of a benevolent demon. Again, if we were to remove the benevolent demon, holding fixed Tim*'s own cognitive contribution to his successes (which is just that of being cognitively constituted such that emotions are reliably triggered for him by the presence of the relevant corresponding values) then Tim*'s evaluative beliefs would be reliably false. $^{28}$

What the case pair contrasting Tim and Tim* demonstrates is that not one but two kinds of emotional skill need to be working in tandem if our emotional experience is going to plausibly justify foundational evaluative beliefs by appropriately causing them. I'll call these two kinds of skill generative emotional skill and doxastic emotional skill.

Generative emotional skill is what Tim lacks, but Tim* possesses. Such skill is needed for a subject (in short) to reliably enough transition from the presence of the relevant values to the generation of the relevant emotions-something that Tim managed only with the help of the benevolent demon, but which Tim* managed by himself, thanks to how he (but not Tim) is cognitively constituted and disposed.

Doxastic emotional skill, by contrast, is what Tim* lacks, but Tim possesses. Such skill is needed for a subject (in short) to reliably enough transition from the presence of the relevant emotion to the generation of the relevant true beliefsomething that Tim* managed only with the help of the benevolent demon, but which Tim managed by himself, thanks to how he is cognitively constituted and disposed.

On the view I favour, when generative emotional skills and doxastic emotional skills are working together in the right way, then emotional experience furnishes one with prima facie justification for foundational evaluative beliefs. The objective in what remains is to explain more clearly (i) the nature of these two forms of emotional skill; and (ii) the mechanisms of their manifestation in those cases where emotional experience plays a justificatory role for foundational beliefs.

Stepping back a moment, though, it is worth noting that if the kind of view I've just suggested can be vindicated, then what results will not be a kind of evaluative foundationalism that jettisons EP wholesale. ${ }^{29}$ Rather, we'll have a revisionary form of EP, one which leaves unchallenged the Perceptual Model's metaphysical thesis

\footnotetext{
${ }^{28}$ For instance, remove the demon, and Tim* reliably feels fear in the presence of what is really fearsome, but then fails in the presence of the triggered emotion to go on to form the belief that the thing in question is fearsome (instead, he believes it is funny, disgusting, etc.).

29 (That is, what results will not be what I've previously referred to as 'non-perceptual modest foundationalism').
} 
that emotions themselves are perceptions of value, while pairing this metaphysical claim with a revised and restricted epistemological claim about the conditions under which emotions suffice to generate prima facie justification and by extension epistemic foundations.

\section{1}

Here is the core statement of view I will now defend:

$(\dagger)$ A subject $S$ 's emotional experience, $E$, furnishes $S$ with prima facie justification for a foundational evaluative belief, $f$, if and only if (i) $f$ issues non-deviantly from the exercise of $S$ 's doxastic emotional competence; and (ii) the input to $S$ 's doxastic emotional competence is an apt emotion-viz., an emotion that manifests S's generative emotional competence.

Several key ideas here need some unpacking. In this section, I will:

(a) Briefly outline the relationship between skill and competence;

(b) Explain, with reference to this general distinction, how generative emotional skill relates to generative emotional competence, and how apt emotion can be defined in terms of generative emotional competence;

(c) Show how doxastic emotional skill relates to doxastic emotional competence, and how prima facie justification arises from emotional experience only when apt emotion issues in the right way from doxastic emotional competence.

\section{1 (a) The difference between skill and competence.}

A competence is, construed broadly, a disposition to perform well reliably enough in a given domain of endeavour; a skill is the key component-the dispositional core-of a competence.

Skills (like competences) correspond with conditionals. They do so in this sense: we typically test for whether one has a skill to do something, $\phi$, by posing a conditional. We want to know: would they $\phi$ successfully reliably enough if they tried (and tried while in proper shape and properly situated). ${ }^{30}$ This latter qualification about 'shape' and 'situation' is important. As Sosa notes, you don't count as lacking the skill to drive a car if it turns out that you wouldn't be able to keep the car on the road if you were drugged with a hallucinogen (improper shape) or placed on unusually slick roads (i.e., improper situation). What counts as being in

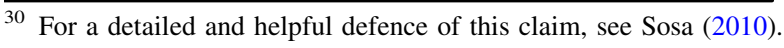


'proper shape' and 'properly situated' varies across domains, and are indexed to the conditions under which performance quality is valued. ${ }^{31}$

On Sosa's picture which I will be assuming, a (complete) competence to $\phi$ requires not only the skill to $\phi$-viz., not only that one would succeed reliably enough when in proper shape and properly situated-but also that one in fact be in proper shape and properly situated.

A final piece of terminology: a performance is apt if and only if it is successful (i.e., it attains the relevant aim) and the success is because of the subject's exercise of a complete competence.

\section{2 (b) Generative emotional skill, generative emotional competence, and apt emotion.}

Recall from our case pair that generative emotional skill is what Tim lacks, but Tim* possesses. Tim managed only with the help of the benevolent demon to reliably enough transition from the presentation of value to the generation of the relevant sort of emotion. Moreover, that Tim* but not Tim possessed this skill seemed to be down to the way that Tim* (but not Tim) was cognitively constituted. Let's now take this idea a bit further.

When one has the skill to drive a car, this disposition is (as Sosa puts it) 'seated in one's brain, nervous system, and body'; the skill in this respect supervenes on this base seated in the agent; it is on account of the subject possessing this supervenience base that the conditional 'the driver would succeed reliably enough in normal conditions if she tried' is true. In a similar vein, emotions are generally taken to have cognitive bases. As Tappolet (2016) puts it:

there are no organs underlying would-be value perceptions. Instead of directly connecting to the world, so to speak, emotions rely on cognitive bases-you need to see or hear, or else to remember or imagine something, to be afraid of it $(2016, \text { pp. 24-25) })^{32}$

\footnotetext{
31 If archery were always performed underwater and never in conditions with ambient oxygen, then we'd test for archery skill by asking whether the subject would perform reliably enough in those conditions. A corollary of Sosa's thinking here is that not all skill/shape/situation (i.e., SSS) dispositions to succeed are competences. As Sosa (2017) puts it: 'Not every disposition to succeed when one tries constitutes a competence [...] although every competence will be constituted by a disposition to succeed when the agent is within certain ranges of shape and situation. A disposition to succeed is thus plausibly made a competence by some prior selection of shape/situation pairs such that one seats a competence only if one is disposed to succeed reliably enough upon trying when in such a shape/situation pair. Whether a particular shape/situation pair is appropriate will, of course, vary from domain to domain of performance' (2017, p. 195).

32 According to some critics of the Perceptual Model, reflection on the role that cognitive bases have to play within EP should lead us to find the epistemic role of emotional experience superfluous. As Brady (2013) puts it, "my fear of the bull cannot be a reason to judge that the bull is dangerous, since then we would have to conclude, from the fact that I am afraid of the bull, that I have good reason to be afraid of the bull. And fear, we might think, cannot justify itself in this way' (2013, p. 113). The present proposal, to be clear, is agnostic about the rationality of emotions themselves; such agnosticism is compatible with accepting the supervenience claim that emotions supervene on cognitive bases (and correspondingly, that emotional skills supervene on cognitive bases). Any version of EP (including the revisionary version
} 
It will suffice for the present purposes to submit that generative cognitive skills, like emotions, will plausibly have cognitive bases of some kind on which they supervene. ${ }^{33}$ To a first approximation, a generative emotional skill supervenes on a cognitive base $\mathrm{C}$ iff $\mathrm{C}$ is such that, when suitably triggered (e.g., by the presence of the relevant values), the subject generates (reliably enough) the appropriate emotion when in proper shape and properly situated. ${ }^{34}$

A (full) generative emotional competence, however, will involve more than the mere possession of generative emotional skill; one has a generative emotional competence iff one has generative emotional skill and, further, is in proper shape and properly situated. On this way of thinking, for example, one fails to possess a full generative emotional competence to generate the emotion of 'admiration' in the presence of what is admirable in a situation wherein one's general disposition to do so is masked by the presence of searing and attention-consuming pain; and this is so even though in such a circumstance one may the relevant skill.

An apt emotion may now be defined in terms of generative emotional competence as follows: an emotion is apt iff it issues (non-deviantly) from the subject's exercise of a generative emotional competence. This is to say, an emotion is apt when it is the product of one's generative emotional skill exercised when the subject is in proper shape and properly situated.

\section{3 (c) Doxastic emotional skill, doxastic emotional competence, and prima facie justification}

Having generated an apt emotion one may still fail to be prima facie justified in taking that emotion at face value when one does. This would be the case if one takes an apt emotion at face value not through any skill we can credit to her. Recall again Tim*. He did not possess any such skill; had the demon not intervened on his behalf, Tim (cognitively constituted as he was) would have failed to transition from the emotional experience of fear he had to any corresponding true evaluative belief.

\footnotetext{
Footnote 32 continued

being advanced here) that wants to make additional claims about epistemic reasons we might have for emotions themselves will need to address worries like the one Brady raises here.

33 This at any rate seems implied by any plausible way of construing the metaphysical component of the Perceptual Model-viz., that emotions are perceptual experiences of value.

34 Two points of clarification are in order here. Firstly, as with other skills, a subject can retain generative emotional skill even when not in proper shape or properly situated. (It doesn't count against one's possessing the relevant generative emotional skill if one does not feel admiration in the presence of someone admirable if one is in severe pain (improper shape) or being held at gun point (improperly situated). Secondly, it's worth noting that generative emotional skill does not have any straightforward analogue in the case of ordinary perception distinct from what would be the perceptual analogue to doxastic emotional skill. It's beyond the scope of the present paper to attempt to defend a positive view of the justification conditions for ordinary perception. But it's worth registering that I think the view is not likely going to fit snugly in the case of ordinary perception. Though this, I think, just is as we should expect: the ways by which one can be more or less competent in the emotional case turn out to be plausibly more varied (see, for example, the twin META-INCOHERENT EMOTER cases) than in the case of ordinary perception.
} 
The kind of skill Tim* lacked is doxastic emotional skill, skill one possesses iff, on account of one's cognitive constitution, one would reliably enough make such a transition, at least, when in proper shape and properly situated. By contrast, one has a full doxastic emotional competence iff one has doxastic emotional skill and, further, is in proper shape and properly situated. On the view I'm proposing, when one's taking not just any emotion, but an apt emotion at face value is because of doxastic emotional competence-viz., one's doing so issues non-deviantly from the exercise of the subject's doxastic emotional competence- then the resultant belief is prima facie justified.

These are the circumstances, then, when emotional experience can bear epistemically on the justification of a foundational evaluative belief by appropriately causing that belief: by involving the manifestation of the two kinds of emotional skill identified. Emotional experience prima facie justifies a belief just when these emotional skills are working together in tandem. This at any rate is a position that I think gives us the best chance of securing a well-structured evaluative epistemology, and it's one on which emotions can be vindicated in an epistemically respectable way as regress stoppers. Though the proposal is not a version of EP to the letter-given that it denies that emotional experience as such has prima facie justificatory force-it shows how certain kinds of emotional experiences do have such force.

I will now turn to considering some anticipated objections to the view as stated. In the course of replying to them, I hope to sharpen some of the details further and flesh out a few additional advantages.

\section{2}

\section{1 (Objection 1)}

The above proposal would constitute a plausible - and suitably anti-scepticalmodest evaluative foundationalism only if emotions really can and do prima facie justify not just a rare few foundational evaluative beliefs, but a sufficiently rich stock of them. (Compare: Sosa's critique of Cartesian foundationalism). But it's hard to see just how the present proposal would manage this. After all, if emotional experience must be backed by two kinds of skill in order to generate prima facie justification, then wouldn't a consequence be that there would be too few foundations?

Reply. First, the present proposal should not be confused with the idea, canvassed previously in our discussion of Pelser, that merely the 'virtuous few' would be in the market for prima facie justification on the basis of their emotional experiences. While it's true that, on the view being advanced, the only kind of emotional experience that can confer prima facie justification is that which manifests both generative and doxastic emotional skill, there is no reason to think such emotional 
experiences would be rare, either in a given community or for any given thinker. ${ }^{35}$ But—on the other side of the coin—nor should we expect such experiences to be simply ubiquitous. On this point, note that traditional versions of the Perceptual Model would have us suppose that evaluative foundations were every bit as ubiquitous as prima facie justified perceptual beliefs. For reasons I've outlined in the opening sections, I think it would not be a virtue of a view if it implied that most or nearly all of our emotional experiences enjoy the status of epistemic foundations, and the view I'm suggesting (rightly) lacks this implication as well.

\section{2 (Objection 2)}

Even if the 'two few foundations' objection can be dealt with, there's a related worry. In short, is the kind of modest foundationalism here really foundationalism at all? Foundationalists after all want to build their 'pyramid' of beliefs on secure foundations. If (as the standard Perceptual Model tells us) emotional experience, as a kind of experience, suffices to justify foundational beliefs, then at least we won't have difficulty working out what our foundations are. But on the view being put forward, it seems like a thinker would have to identify which emotions are the apt ones that issue from generative doxastic skill before ever successfully identifying which beliefs are the foundational beliefs. But wouldn't we very easily be mistaken about this? If so, then in what sense have we 'secured' such epistemic foundations?

Reply. Some would more easily be mistaken than others, and this will vary depending on one's ability to place one's own generative and doxastic skills in perspective. But more importantly at present, the above worry seems to take for granted a way of thinking about epistemic foundations that aligns itself with epistemic internalism. Consider, after all, that for any belief with positive epistemic status, $X$, an epistemic externalist with respect to that status can permit a belief to have that status in the absence of the agent knowing that the conditions that would need to be in place for the belief to have that status are satisfied. The force of the above objection, then, is vitiated once we appreciate that the objection overgeneralises so as to apply to any kind of externalist approach to epistemic foundations, and not just the present externalist proposal.

\section{3 (Objection 3)}

Even if that is granted, it seems there's another sense in which the requirements this proposal is making on prima facie justification might be too strong. The worry goes as follows: (a) presumably, some prima facie justified beliefs will be false. And yet,

\footnotetext{
35 Consider here a comparison with understanding. Objectual understanding-viz., as when we understand a subject matter of a body of information-is, in one sense, intellectually demanding: it arguably cannot be simply acquired simply by, say, blind trust in the absence of the kind of intellectual sophistication that is involved in grasping (in a suitably skilful way) the relevant explanatory relationships between the propositions making up the body of information (e.g., Kvanvig 2003). And yet, understanding is not, despite demanding such intellectual sophistication, rare; most people understand a good deal of things. We should resist the suggestion that doxastic and generative skill are rare, even if, a propos Pelser, fully virtuous individuals are.
} 
(b) it's not immediately clear how the proposal being advanced can make sense of that given the requirement that such beliefs issue from doxastic generative competence. Wouldn't that just imply that all prima facie justified beliefs are also true?

Reply. In short, no. Competences, like the skills they are composed of, are not dispositions the exercise of which requires perfect reliability. Recall that a skill, generally speaking, is a disposition to perform reliably enough when in the right shape and situation, and perfect reliability isn't entailed by simply being in proper shape and properly situated. ${ }^{36}$ In the case of most epistemic competences, of which doxastic emotional competence is an instance, reliably enough means (roughly) most of the time. Thus, the view is entirely compatible with the countenancing of prima facie justified but false beliefs.

\section{4 (Objection 4)}

The case pair discussed (with Tim and Tim*) shows that generative emotional skill and doxastic emotional skill can come apart, in the sense that a subject can possess and exercise one kind of emotional skill in the absence of the other. While this in and of itself seems plausible, it also seems to have a somewhat odd implication. Note that if someone has a high level of generative emotional skill, then the level of doxastic emotional skill the subject needs to command seems to be pretty marginal. In the limiting case where one's generative emotional skill is maximally reliable, then all doxastic emotional skill would require would be to invariably take one's emotions at face value, right? But how is that even a skill? Couldn't someone do the same job through naivety?

Reply. The initial observation here is correct, though the implication is exactly what we should expect. That this is so has been discussed, analogically, by John Greco (2007, pp. 65-66) in his work on easy achievements ${ }^{37}$ and their relationship to testimonial knowledge. Here it will be helpful to consider, as Greco does, two versions of a soccer example. In the the first version of the case, Ted receives a great pass and then scores an easy goal with little effort displayed on his part. Yet, we still intuitively credit him for the goal (even if the passer also deserves credit.) In the second version of the case, Ted is not paying attention and, as Greco puts it: "never seeing the ball, a brilliant pass bounces off his head and into the goal. Here Ted does not deserve credit for the goal. He was involved in a way, but not in the right sort of way' (2007, p. 65). By 'right sort of way', Greco means that the success was not because of any reliable ability or competence of Ted's. Greco suggests that, even in the first version of the case wherein Ted didn't need to display much effort, it

\footnotetext{
36 Proper shape and situation, as was noted, are circumscribed with reference to conditions under which good performance is generally valued. And it's not the case that we generally value good performance only when one is a in success ensuring shape or situation.

37 For the present purposes, the 'achievement' locution is not important. Rather, what matters at present is that (since achievement involves the exercise of ability) Greco is suggesting how such exercise may on occasion may be very easy and require very little effort on the part of the agent. For our purposes, then, nothing hangs on whether the further point about achievement goes through.
} 
remains that he exercised an ability (i.e., to shoot reliably from close range), an ability the possession of which clearly serves good soccer players well (unlike the disposition to just stand there and hope for the ball to bounce off you the right way).

Although Greco uses his soccer analogy, dialectically, in order to make a point about testimony - namely that the possession of the ability to reliably accept expert testimony is one that serves good inquirers well despite not involving much by way of effort or skill —an analogy to our present case is germane as well. Just consider that the reliable exercise of generarive emotional skill places one in an epistemic position that resembles the soccer player who receives great passes; or the recipient of highly reliable testimony. In all three cases, reliable performance on the part of the recipient is valued, even when the acquisition of the relevant good is easy to attain; and furthermore, in all such cases, we can draw a meaningful distinction between (i) the exercise of a competence that takes little effort and (ii) lucky but incompetent success.

\section{5 (Objection 5)}

The model proposed offers an explanation for how emotions can, in the right circumstances, give rise to prima facie justified beliefs which themselves can play the role of epistemic foundations. But what it has not explained is how such prima facie justified beliefs might rise to the level of knowledge.

Reply. That is right. The principal project here has been to show how emotional experience of a particular sort can prima facie justify evaluative beliefs, and ipso facto, halt a justificatory regress by the lights of modest foundationalism. There is a live debate over whether, even if emotions can prima facie justify beliefs, they can also ever suffice to ultima facie justify beliefs (where even ultima facie justified beliefs may fall short ${ }^{38}$ of knowledge). ${ }^{39}$ While it's beyond the scope of the present paper to weigh in on this further debate, I think the present account offers exactly the kind of materials that would be needed to answer in the affirmative. This is, in particular, due to the fact that (i) prima facie justification is explained on the account advanced in terms of competence; and (ii) according to virtue epistemology, knowledge can itself be straightforwardly modelled in terms of competence.

A simple statement of the core idea embraced by virtue epistemologists is that a subject knows a proposition just in case her believing truly is because of her

\footnotetext{
38 Ultima facie justified beliefs and knowledge famously come apart in traditional Gettier cases, where the former is present and the latter (due to knowledge-undermining epistemic luck) is not. See, e.g., Gettier (1963).

39 For example, according to Brady (2010), normative 'why' questions are always appropriate in the case of emotions, even though they're not in the case of perceptual experience, and this casts doubt on the thought that emotional experiences will ever provide sufficient or ultima facie justification - they at most on his view secure what he calls 'proxy justification'. (Compare: "why are you afraid of that dog" or "why are you in awe of that painting" (2010) seem like perfectly reasonable questions, where as "why do you see a coat in the closet" or "why do you hear music" do not.) This leads Brady to suggest that "there is a difference in the epistemic strength of perceptual and emotional experience', a difference whereby we should not regard emotional experience as capable of furnishing sufficient justification even if perceptual experience is. For a response to this line of objection, see Mitchell (2017).
} 
intellectual ability or virtue. ${ }^{40}$ To a first approximation, we can easily envision a special case of this more general formula taking the following shape: If $S$ 's true evaluative belief $p$ is because of her doxastic emotional competence which has as an input an apt emotion, then $S$ knows that $p$. Note that what's being suggested here is merely a sufficient and not a necessary condition for evaluative knowledge because, as Brady (2010, 81-82) rightly notes, emotional experiences are not the only sources of evaluative beliefs and knowledge. Nonetheless, if a virtue-theoretic account of knowledge more generally is viable, then we have a straightforward explanation for how emotional experience can (under the right circumstances) give rise to evaluative knowledge. There are well-known caveats and qualifications that the general virtue-theoretic account of knowledge might need take on board in to avoid objections that have been raised to the proposal, ${ }^{41}$ and any special instance of the general formula will need to do the same. In particular, such an account will need to address what we might call 'emotional fake barn cases'—viz., cases where one's true belief is because of doxastic emotional competence even though the target belief is modally unsafe due to the presence of near-by error possibilities. But how to address such cases will have to be a task for another day.

Acknowledgements Thanks to Robert Cowan, Emma C. Gordon, Eilidh Harrison and Chris Kelp for detailed comments on previous versions of this paper. I'm also grateful to an audience at the 2018 World Congress of Philosophy in Beijing, China, as well as to an anonymous referee at Philosophical Studies.

Open Access This article is distributed under the terms of the Creative Commons Attribution 4.0 International License (http://creativecommons.org/licenses/by/4.0/), which permits unrestricted use, distribution, and reproduction in any medium, provided you give appropriate credit to the original author(s) and the source, provide a link to the Creative Commons license, and indicate if changes were made.

\section{References}

BonJour, L. (1985). The structure of empirical knowledge. Cambridge: Cambridge University Press.

Brady, M. S. (2010). Virtue, emotion, and attention. Metaphilosophy, 41(1-2), 115-131.

Brady, M. S. (2013). Emotional insight: The epistemic role of emotional experience. Oxford: Oxford University Press.

Burge, T. (1993). Content preservation. Philosophical Review, 102(4), 457-488.

Carter, J. A., \& Littlejohn, C. (2019). This is epistemology. Wiley-Blackwell.

Carter, J. A., \& Pritchard, D. (2019). Extended Entitlement. In G. Peter and J.L.L.P. Nikolaj (Eds.), New essays on entitlement. Oxford: OUP.

Cowan, R. (2016). Epistemic perceptualism and neo-sentimentalist objections. Canadian Journal of Philosophy, 46(1), 59-81.

Davidson, D. (1986). A coherence theory of truth and knowledge. In E. LePore (Ed.), Truth and interpretation. Perspectives on the philosophy of donald davidson (pp. 307-319). Hoboken: Blackwell.

Döring, S. A. (2003). Explaining action by emotion. The Philosophical Quarterly, 53(211), 214-230.

\footnotetext{
${ }^{40}$ For some representative defences of this position, see, e.g., Greco (2003, 2010) and Sosa (2009, 2015).

41 See, for example, Lackey (2007), Pritchard (2012) and Kallestrup and Pritchard (2014).
} 
Döring, S. A. (2007). Seeing what to do: Affective perception and rational motivation. Dialectica, 61(3), 363-394.

Echeverri S. S. (2017). Emotional justification. Philosophy and Phenomenological Research.

Elgin, C. Z. (2008). Emotion and understanding. In D. B. Georg \& D. Kunzle (Eds.), Epistemology and emotions (pp. 33-50). Farnham: Ashgate Alderchot.

Gettier, E. (1963). Is justified true belief knowledge? Analysis, 23(6), 121-123.

Goldman, A. I. (2008). Immediate justification and process reliabilism. In Q. Smith (Ed.), Epistemology new essays (pp. 63-82). Oxford: Oxford University Press.

Graham, P. J. (2011). Perceptual entitlement and basic beliefs. Philosophical Studies, 153(3), 467-475.

Greco, D. (2017). Cognitive mobile homes. Mind, 126(501), 93-121.

Greco, J. (2003). Knowledge as credit for true belief. In M. DePaul \& L. Zagzebski (Eds.), Intellectual virtue: Perspectives from ethics and epistemology. Oxford: Oxford University Press.

Greco, J. (2007). The nature of ability and the purpose of knowledge. Philosophical Issues, 17(1), 57-69.

Greco, J. (2010). Achieving knowledge: A virtue-theoretic account of epistemic normativity. Cambridge: Cambridge University Press.

Greenspan, P. (1988). Emotions and reason: An inquiry into emotional justification. New York: Routledge.

Haddock, A., Millar, A., \& Pritchard, D. (2010). The nature and value of knowledge: Three investigations. Oxford: Oxford University Press.

Hasan, A., \& Fumerton, R. (2017). Foundationalist theories of epistemic justification. In E. N. Zalta (Ed.), The stanford encyclopedia of philosophy. Spring, Metaphysics Research Lab, Stanford University. https://plato.stanford.edu/archives/spr2017/entries/justep-foundational/. Accessed July 2018.

Huemer, M. (2001). Skepticism and the veil of perception. Lanham: Rowman \& Littlefield.

Kallestrup, J., \& Pritchard, D. (2014). Virtue epistemology and epistemic twin earth. European Journal of Philosophy, 22(3), 335-357.

Kelp, C. (2016). Epistemic Frankfurt cases revisited. American Philosophical Quarterly, 53(1), $27-37$.

Kvanvig, J. (2003). The value of knowledge and the pursuit of understanding. Cambridge: Cambridge University Press.

Lackey, J. (2007). Why we don't deserve credit for everything we know. Synthese, 158(3), 345-361.

Lyons, J. C. (2009). Perception and basic beliefs: Zombies, modules and the problem of the external world. New York: Oxford University Press.

Markie, P. J. (2005). The mystery of direct perceptual justification. Philosophical Studies, 126(3), $347-373$.

Markie, P. J. (2010). The power of perception. In E. S. J. Dancy \& M. Steup (Eds.), A companion to epistemology (pp. 62-74). Oxford: Blackwell Oxford.

McGrath, M. (2013). Phenomenal conservatism and cognitive penetration: The? Bad basis? Counterexamples. In C. Tucker (Ed.), Seemings and iustification: New essays on dogmatism and phenomenal conservatism (pp. 225-247). Oxford: Oxford University Press.

Mitchell, J. (2017). The epistemology of emotional experience. Dialectica, 71(1), 57-84.

Olsson, E. (2014). Coherentist theories of epistemic justification. In E.N. Zalta (Ed.), The stanford encyclopedia of philosophy, Spring. http://plato.stanford.edu/archives/spr2014/entries/justepcoherence/. Accessed July 2018.

Pelser, A. C. (2014). Emotion, evaluative perception, and epistemic justification. In S. Roeser \& C. Todd (Eds.), Emotions and values (pp. 107-123). Oxford: Oxford University Press Oxford.

Pollock, J. (1986). Contemporary theories of knowledge. Savage: Rowman \& Littlefield Publishers.

Pritchard, D. (2012). Anti-luck virtue epistemology. Journal of Philosophy, 109(3), 247-279.

Pryor, J. (2000). The skeptic and the dogmatist. Nô̂s, 34(4), 517-549.

Pryor, J. (2004). What's wrong with Moore's argument? Philosophical Issues, 14(1), 349-378.

Roberts, R. C. (2003). Emotions: An essay in aid of moral psychology. Cambridge: Cambridge University Press.

Sellars, W. (1956). Empiricism and the philosophy of mind. Minnesota Studies in the Philosophy of Science, 1(19), 253-329.

Siegel, S. (2012). Cognitive penetrability and perceptual justification. Nô̂s, 46(2), 201-222.

Sosa, E. (1980). The raft and the pyramid: Coherence versus foundations in the theory of knowledge. Midwest Studies in Philosophy, 5, 3-25.

Sosa, E. (1997). Mythology of the given. History of Philosophy Quarterly, 14(3), 275-286.

Sosa, E. (2009). Reflective knowledge: Apt belief and reflective knowledge (Vol. 2). Oxford: Oxford University Press. 
Sosa, E. (2010). How competence matters in epistemology. Philosophical Perspectives, 24(1), 465-475.

Sosa, E. (2015). Judgment and agency. Oxford: Oxford University Press.

Sosa, E. (2017). Epistemology. Princeton: Princeton University Press.

Tappolet, C. (2012). Emotions, perceptions, and emotional illusions. In C. Clotilde (Ed.), Perceptual illusions. Philosophical and psychological essays (pp. 207-24). Palgrave Macmillan.

Tappolet, C. (2016). Emotions, value, and agency. Oxford: Oxford University Press.

Tucker, C. (2010). Why open-minded people should endorse dogmatism. Philosophical Perspectives, 24(1), 529-545.

Turri, J., \& Klein, P. D. (2014). Ad infinitum: New essays on epistemological infinitism. Oxford: Oxford University Press.

Williams, M. (2007). Why (Wittgensteinian) contextualism is not relativism. Episteme, 4(1), 93-114.

Publisher's Note Publisher's Note Springer Nature remains neutral with regard to jurisdictional claims in published maps and institutional affiliations. 